\title{
Partial Delegation in a Model of Currency Crisis
}

\author{
Virginie Boinet*
}

\begin{abstract}
Stressing the influence of expected devaluation on currency crises, this paper shows that, in a fixed exchange-rate system with an escape clause, partial delegation of exchange-rate policy to an inflation-averse central banker reduces the probability of crisis.
\end{abstract}

Keywords: Currency crisis; Multiple equilibria; Credibility; Monetary delegation

JEL classification: E52; F41

\section{Introduction}

A well-known result in the literature on currency crisis is that the cost of defending a fixed rate increases when private agents expect a devaluation (Krugman, 1998). In this context, this paper considers partial delegation of exchange-rate policy to a central banker who is more inflation averse than the government: the decision as to whether to maintain the peg is left to the government, but the magnitude of any realignment is delegated to the central banker. Looking at the influence of expected devaluation, it shows that, in a fixed exchangerate system with an escape clause, this partial delegation reduces the probability of crisis. In particular, it underlines the fact that it is more effective to devolve exchange-rate policy when private agents expect a future realignment, as the reduction of the probability of crisis

\footnotetext{
*Department of Economics and Finance, Brunel University, Uxbridge, Middlesex, UB8 3PH, UK. Tel: ++44-1895-203386, fax: ++441895-203384. E-mail address: Virginie.Boinet@brunel.ac.uk.

I would like to thank John Bennett, Eric Girardin, Christos Ioannidis and Chris Martin for very helpful comments.
} 
is greater. These results are strengthened if the central banker's degree of inflation aversion is greater, for the probability of self-fulfilling crisis is reduced and the stability of the fixed exchange-rate system increased.

\section{Partial delegation}

\subsection{The model}

The framework is based on a model of currency crisis à la Obtsfeld (1994). In a small open economy, the log of employment $n$ can be expressed by

$$
n=n^{*}+\rho\left(\Pi-\Pi^{e}\right) \quad n^{*}=0, \rho>0
$$

where $\Pi$ and $\Pi^{e}$ denote actual and expected inflation. The natural employment rate $n^{*}$ is assumed to be zero. Inflation expectations are formed at the beginning of the period as private agents sign nominal contracts. Then firms determine the demand for labor and the policy maker decides whether to maintain the peg.

Purchasing Power Parity (PPP) holds. Foreign prices are exogenous and normalized to 1. Control of exchange-rate variations $\Delta e$ and of the inflation rate $\Pi$ are therefore equivalent. The aim of exchange-rate or monetary policy is to minimize deviations of inflation and employment from their target levels. The loss functions of the government and the central banker are respectively

$$
\begin{aligned}
& L^{G}=\frac{1}{2} \stackrel{\mathfrak{f}}{\Pi^{2}}+(n-\mathbf{e})^{2^{\mathfrak{a}}}+\Omega C \\
& L^{C B}=\frac{1}{2}{ }^{\mathfrak{f}}(1+\varepsilon) \Pi^{2}+(n-\mathbf{e})^{2^{\mathfrak{\alpha}}}
\end{aligned}
$$

The target level of employment $\mathrm{e}$ is above the natural rate, and so can be interpreted as an inflationary bias. The inflation target is zero. $C$ represents the realignment cost incurred by the policy maker (in terms of credibility for instance) after the abandonment of the peg. Consequently, $\Omega$ is a binary variable equal to 0 when the policy maker maintains the peg and equal to 1 when he devalues. We assume partial delegation of exchange-rate policy to a central banker who has the same targets as the policy maker but who places greater weight 
on the costs of higher inflation $(\varepsilon>0) .{ }^{1}$ There is no cost of realignment to the central banker because it is the government that decides whether realignment occurs. Therefore, when the policy maker decides to devalue, exchange-rate policy is delegated to the central banker and $\Delta e$ is determined such that $\frac{\partial L^{\mathrm{B} C}}{\partial \Delta e}=0$, that is,

$$
\Pi=\Delta e=\frac{\rho}{1+\varepsilon+\rho^{2}}\left(\rho \Pi^{e}+\mathbf{e}\right)
$$

The more the central banker is inflation averse ( $\varepsilon$ high), the smaller is the influence of inflationary expectations and the employment target on the devaluation rate.

Information available for the formation of inflation expectations is the same as that for the policy maker except that private agents do not know the realignment $\operatorname{cost} C$. Therefore, they cannot perfectly forecast the final decision of the policy maker. If economic agents expect the maintenance of the peg, then $\Pi^{e}=0$. If they expect a devaluation, $\Pi^{e}=\Pi$, that is,

$$
\Pi^{e}=\frac{\rho}{1+\varepsilon} \mathbf{e}
$$

Inflation expectations increase with the inflationary bias while they decrease with the central banker's degree of inflation aversion.

\subsection{The realignment condition and effects of partial delegation}

When the government defends the peg, it follows that $\Pi=\Delta e=0$. When it proceeds to a realignment, $\Pi$ is expressed by equation (4). Inserting (1) into (2), the government's loss in the two respective situations is found as

$$
\begin{aligned}
L_{F X}^{G} & =\frac{1}{2}\left(\rho \Pi^{e}+\mathbf{e}\right)^{2} \\
L_{F L}^{G} & =\frac{\rho^{2}+(1+\varepsilon)^{2}}{2\left(1+\varepsilon+\rho^{2}\right)^{2}}\left(\rho \Pi^{e}+\mathbf{e}\right)^{2}+C
\end{aligned}
$$

\footnotetext{
${ }^{1}$ The delegation is partial as there is a cost to the government when a realignment occurs. To take this cost into account, the decision as to whether to maintain the peg is left to the government, but the magnitude of any realignment is delegated to the central banker.
} 
This loss depends positively on inflation expectations and the inflationary bias. As a result, the policy maker will decide to devalue if $L_{F X}^{G}-L_{F L}^{G}>0$, that is,

$$
\frac{\rho^{2}\left(1+2 \varepsilon+\rho^{2}\right)}{2\left(1+\varepsilon+\rho^{2}\right)^{2}}\left(\rho \Pi^{e}+\mathbf{e}\right)^{2}>C
$$

This inequality indicates that the probability of realignment increases when expected inflation and the inflationary bias are higher and when the realignment $\operatorname{cost} C$ is smaller.

Taking into account inflation expectations, thresholds under which the government will decide to devalue are equal to

$$
\begin{aligned}
& \underline{C}_{1}^{W D}=\frac{\rho^{2}\left(1+2 \varepsilon+\rho^{2}\right)}{2\left(1+\varepsilon+\rho^{2}\right)^{2}} \mathbf{e}^{2} \\
& \underline{C}_{2}^{W D}=\frac{\rho^{2}\left(1+2 \varepsilon+\rho^{2}\right)}{2(1+\varepsilon)^{2}} \mathbf{e}^{2}
\end{aligned}
$$

$\underline{C}_{1}^{W D}$ is the threshold which prevails when private agents expect no devaluation $\left(\Pi^{e}=0\right)$, while $\underline{C}_{2}^{W D}$ is the threshold which prevails when private agents expect a realignment $\left(\Pi^{e}=\Pi\right)$. Note that $\underline{C}_{1}^{W D}$ and $\underline{C}_{2}^{W D}$ are both positive and that $\underline{C}_{1}^{W D}<\underline{C}_{2}^{W D}$. At one threshold $\underline{C}_{2}^{W D}$, as inflationary expectations are high, competitiveness and unemployment problems are so painful that a devaluation occurs unless the realignment cost is very high. At the other threshold $\underline{C}_{1}^{W D}$, the policy maker will maintain the peg even if the realignment cost is low. Multiple equilibria occur between $\underline{C}_{1}^{W D}$ and $\underline{C}_{2}^{W D}$. Therefore, if $C$ belongs to this interval, the government can either defend the peg or realign. The decision depends on private agents' expectations. This implies that crises are self-fulfilling.

We consider here delegation to a central banker who is more inflation averse than the government. $\varepsilon=0$ represents the case of no delegation as then government and central banker have exactly the same preferences and targets. Let $\underline{C}_{i}^{N D}$, where $i=1,2$, denote thresholds obtained when the government does not delegate exchange-rate policy. Putting $\varepsilon=0$ into (9) and (10),

$$
\begin{aligned}
& \underline{C}_{1}^{N D}=\frac{\rho^{2}}{2\left(1+\rho^{2}\right)} \mathbf{e}^{2} \\
& \underline{C}_{2}^{N D}=\frac{\rho^{2}\left(1+\rho^{2}\right)}{2} \mathbf{e}^{2}
\end{aligned}
$$

Note that $\underline{C}_{1}^{N D}$ and $\underline{C}_{2}^{N D}$ are both positive and that for the same reasons as previously $\underline{C}_{1}^{N D}<\underline{C}_{2}^{N D}$. The comparison of these different thresholds leads to the following proposition. 
Proposition 1. Partial delegation of exchange-rate policy to a more inflation-averse central banker reduces the level of the thresholds.

This proposition is confirmed by the following inequality.

$$
\underline{C}_{i}^{W D}<\underline{C}_{i}^{N D} \quad \text { where } i=1,2
$$

So, whatever private agents' expectations, with partial delegation to a more inflation-averse central banker, the probability of crisis is reduced. The policy maker maintains the peg while the cost of realignment is smaller. This result can be explained by the negative (downward) influence of partial delegation on expected inflation. As the cost of defending a fixed rate decreases when private agents expect its maintenance, the probability of crisis is reduced. This suggests that the effect of partial delegation on the probability of crisis is more effective when private agents expect a future realignment. This idea is confirmed by the proposition below.

Proposition 2. Partial delegation of exchange-rate policy to a more inflation-averse central banker decreases the gap between the two thresholds.

This proposition gives additional information concerning the evolution of thresholds. Proposition 1 indicates that, with partial delegation, the probability of crisis is reduced at each threshold. Proposition 2 specifies that the probability of crisis is reduced more at $\underline{C}_{2}^{W D}$ than at $\underline{C}_{1}^{W D}$. Therefore, as the peg is more fragile at $\underline{C}_{2}^{W D}$ and the strategy of partial delegation more efficient, expectations of devaluation strengthen the need of implementing this strategy. It is confirmed by the following inequality.

$$
\underline{C}_{2}^{W D}-\underline{C}_{1}^{W D}<\underline{C}_{2}^{N D}-\underline{C}_{1}^{N D}
$$

As illustrated in Figure 1, the area of multiple equilibria is reduced. We write 1 when the government devalues and 0 when it defends the peg. The first number indicates the policy maker's decision in the case of no delegation and the second number the policy maker's decision when exchange-rate policy is partially delegated to a more inflation-averse central banker. 
Policy maker's
decision

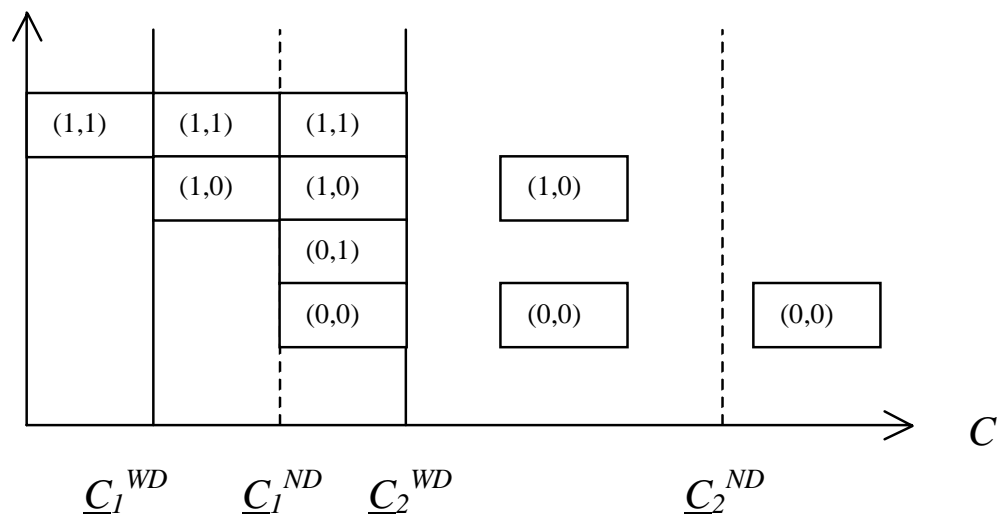

Figure 1

Whether $\underline{C}_{2}^{W D} \lessgtr \underline{C}_{1}^{N D}$ depends on the value of $\varepsilon$. Using (9) and (10), we find

$$
\begin{aligned}
\frac{\partial \underline{C}_{i}^{W D}}{\partial \varepsilon} \boldsymbol{\phi} & <0 \quad \text { where } i=1,2 \\
\frac{\partial^{\mathrm{i}} \underline{C}_{2}^{W D}-\underline{C}_{1}^{W D}}{\partial \varepsilon} & <0
\end{aligned}
$$

Thus, we obtain the following proposition.

Proposition 3. The more the central banker is inflation averse,

i) the lower is the level of thresholds;

ii) the smaller is the gap between the two thresholds.

This last proposition means that, whatever inflation expectations, the probability of crisis decreases with the central banker's degree of inflation aversion and that the magnitude of this reduction is higher when private agents expect a devaluation. If $\varepsilon$ is very high, expected inflation is close to zero (see (5)). Then, $\underline{C}_{1}^{W D}$ is lower and the interval between $\underline{C}_{2}^{W D}$ and $\underline{C}_{1}^{W D}$ substantially decreases. At the extreme, $\underline{C}_{1}^{W D}$ is close to zero and $\underline{C}_{2}^{W D}$ close to $\underline{C}_{1}^{W D} \cdot \underline{C}_{2}^{W D}$ then becomes smaller than $\underline{C}_{1}^{N D}$. Self-fulfilling crises are avoided. One threshold remains at which the probability of crisis is considerably reduced. 


\section{References}

[1] Barro, R. and D. B. Gordon, 1983, A Positive Theory of Monetary Policy in a Natural Rate Model, Journal of Political Economy 91, 589-610.

[2] Krugman, P., 1979, A Model of Balance of Payments Crises, Journal of Money, Credit and Banking 11, 311-325.

[3] Krugman, P., 1996, Are Currency Crises Self-Fulfilling?, NBER Annual Macroeconomics, 345-378.

[4] Krugman, P., 1998, Currency Crises, http://web.mit.edu/krugman/www/crises.html.

[5] Kydland, F. and E. Prescott, 1977, Rules Rather than Discretion : the Inconsistency of Optimal Plans, Journal of Political Economy 85, 473-491.

[6] Loisel, O. et P. Martin, 2001, Coordination, Cooperation, Contagion and Currency Crises, Journal of International Economics 53, 399-419.

[7] Obstfeld, M., 1994, The Logic of Currency Crises, Cahiers Economiques et Monétaires 43, 189-213.

[8] Rogoff, K., 1985, The Optimal Degree of Commitment to an Intermediate Monetary Target, Quarterly Journal of Economics 100, 1169-1190. 